\title{
Época de aplicação de fungicida na cultura do milho segunda safra
}

\author{
Lia Mara Moterle ${ }^{1}$, Renato Frederico dos Santos ${ }^{2}$ \\ ${ }^{1}$ Universidade Federal do Paraná - UFPR. ${ }^{2}$ Universidade Estadual de Maringá - UEM. E-mail: Imoterle@hotmail.com
}

\begin{abstract}
Resumo
Uma das limitações da expressão do potencial produtivo de híbridos de milho é a ocorrência de doenças foliares na cultura. $O$ ajuste da época de aplicação dos fungicidas é essencial para haver sucesso no controle das principais doenças, e consequentemente, aos danos ocasionados pelas mesmas. Sendo assim, este trabalho teve como objetivo avaliar a época de aplicação de fungicida, em diferentes estádios de desenvolvimento da cultura do milho de segunda safra. Para tanto, foram conduzidos dois experimentos no município de Astorga-PR, em delineamento de blocos completos com tratamentos aleatorizados e cinco repetições. Os tratamentos avaliados foram compostos por quatro épocas de aplicação de fungicida (Trifloxistrobina $100 \mathrm{~g} \mathrm{~L}^{-1}+$ Tebuconazol $200 \mathrm{~g} \mathrm{~L}^{-1}$ ): V8, Pré-Florescimento, V8 + Pré-Florescimento e testemunha. As aplicações do fungicida Trifloxistrobina + Tebuconazol em Pré-Florescimento e V8 + PréFlorescimento reduziram a severidade de Cercosporiose e Helmintosporiose na cultura do milho de segunda safra. A maior produtividade da cultura do milho foi obtida quando das aplicações de fungicida em V8 + Pré-Florescimento.
\end{abstract}

Palavras-chave: estádio; doenças; severidade; produtividade.

\section{Application time of fungicide in the culture of corn second safra}

\begin{abstract}
One of the limitations of the expression of the productive potential of maize hybrids is the occurrence of foliar diseases in the crop. The adjustment of the time of application of the fungicides is essential to have success in controlling the main diseases, and consequently, the damages caused by them. Thus, this work had the objective of evaluating the time of the fungicide application, at different stages of development of maize second safra. For that, two experiments were carried out in the city of Astorga-PR, in a complete block design with randomized treatments, with five replications. The evaluated treatments were composed by four fungicide (Trifloxistrobina $100 \mathrm{~g} \mathrm{~L}^{-1}+$ Tebuconazol $200 \mathrm{~g} \mathrm{~L}^{-1}$ ) application times: V8, Pre-Flowering, V8 + Pre-Flowering, in addition to the control. The applications of the fungicide Trifloxystrobin + Tebuconazole in Pre-Flowering and V8 + Pre-Flowering reduced the severity of Cercosporiosis and Helmintosporiosis in second crop maize. The highest productivity of the maize crop was obtained when V8 + Pre-Flowering fungicide applications were performed.
\end{abstract}

Keywords: stadium; diseases; severity; grain yield.

\section{Introdução}

A cultura do milho (Zea mays L.) se destaca, há décadas, no cenário agrícola brasileiro. Sua importância se deve a sua versatilidade de uso na alimentação animal, na forma de grão, forrageira ou transformado em ração; na alimentação humana, como guloseimas e fabricação de derivados; bem como, na indústria de alta tecnologia, como na produção de etanol (DUARTE et al., 2018).

Da produção total de milho estimada, de 85 milhões de toneladas, na safra 2017/2018, 68 $\%$ são representadas pelo milho segunda safra (CONAB, 2018). Esses dados refletem a importância da implementação da safrinha, que, em conjunto com o incremento das exportações 
ao longo da última década, foram fundamentais para alavancar a produção brasileira (KIST et al. 2018).

O cultivo desta espécie, por ter ampla abrangência geográfica, devido à sua alta variabilidade genética, está sujeita a diversos fatores, tais como: disponibilidade hídrica, fertilidade do solo, densidade de plantas, sistema de cultivo, plantas daninhas, pragas e doenças. Dessa forma, o ataque de diversas doenças é comum nesta cultura, as quais podem acarretar em perdas significativas, na sua produtividade. Entre essas, destacam-se as manchas foliares ocasionadas por fungos como a Ferrugem, a Helmintosporiose e a Cercosporiose (BRITO et al., 2012; COSTA et al., 2012; SILVA et al., 2012; BRITO et al., 2013).

A Ferrugem Comum (Puccinia sorghi) pode surgir no início do desenvolvimento da cultura, debilitando a planta e permitindo a ocorrência de outros patógenos (BRANDÃO et al., 2003; DUARTE et al., 2009).

A Helmintosporiose (Exserohilum turcicum) ocasiona perdas que superam $40 \%$ da produção de grãos em cultivares de milho suscetíveis, e seus sintomas aparecem, primeiramente, nas folhas mais velhas (COTA et al., 2013).

A Cercosporiose (Cercospora zeae-maydis), por sua vez, tem a capacidade de redução de 20 a $60 \%$ na produção do milho, dependendo da suscetibilidade do híbrido e do clima (FANTIN et al., 2008; GONÇALVES et al., 2012; SILVA et al., 2012). Em alta severidade, associada a materiais suscetíveis, a redução pode chegar a ultrapassar os 80\% (BRITO et al., 2011; GRIGOLLI et al., 2016).

Os danos associados às doenças foliares se devem ao fato dos patógenos colonizarem grande parte do tecido foliar, diminuindo a área fotossintetizante, levando à necrose e senescência precoce e, consequentemente, à redução da produtividade de grãos (GONÇALVES et al., 2012; FARIA et al., 2015).

De acordo com Fancelli (1988), próximo à antese, a destruição de $25 \%$ da área foliar da planta de milho em sua porção terminal, pode causar redução de $32 \%$ na produção de grãos. Além disso, a folha da espiga e as folhas imediatamente abaixo e acima da espiga podem representar de 33 a $40 \%$ da área foliar total da planta (PATAKY, 1992; LAGO; NUNES, 2008; VILELA et al., 2012) e, quando afetadas severamente pelas doenças supracitadas, podem provocar danos irreparáveis na produtividade da cultura, pela redução do número, tamanho e peso (densidade) total de grãos (FANCELLI, 1988).

As doenças da cultura do milho apresentam elevado grau de variabilidade espacial e temporal. Dessa forma, ocorrem incertezas no momento da tomada de decisão do melhor método de controle, como a utilização de fungicidas e época de aplicação (COSTA et al., 2012; ECCO et al. 2014). Nos últimos anos, a preocupação com o controle de doenças, que atacam no período de final de ciclo, com a utilização de fungicidas químicos sintéticos em aplicações foliares, tem aumentado. Costa et al. (2012) e Gonçalves et al. (2012) relataram que a época de aplicação de fungicidas pode influenciar sua eficácia.

Esta prática de manejo vem ocasionando discussões entre produtores e técnicos e não está totalmente elucidada (LAGO; NUNES, 2008; DUARTE et al., 2009; VILELA et al., 2012; SILVA et al., 2016).

Dessa forma, este trabalho teve como objetivo avaliar a época de aplicação de fungicida, em diferentes estádios fenológicos, visando o controle das principais doenças da cultura do milho, cv AG 9010, na segunda safra.

\section{Material e Métodos}

O trabalho foi conduzido na área experimental do Centro Universitário Ingá, localizada no município de Astorga, Estado do Paraná, com coordenadas de latitude $23^{\circ} 16^{\prime} 53^{\prime \prime} \mathrm{S}$ e longitude 51049'33" W. Foram conduzidos dois experimentos, um em 2014 e outro em 2015, nos períodos de segunda safra. Para este fim, foi utilizado o híbrido AG 9010, cuja semeadura foi efetuada nos dias 15 e 19 de março e a colheita nos dias 9 e 3 de agosto, nas safras de 2014 e 2015, respectivamente.

O híbrido AG 9010, fornecido pela empresa Monsanto, apresenta as seguintes características: ciclo superprecoce, excelente sistema radicular e qualidade de colmo, porte baixo, baixa inserção de espiga, bom empalhamento, grão duro alaranjado, recomendado para semeadora na safra verão e safrinha e população recomendada na safrinha $55.000-65.000$ plantas ha ${ }^{-1}$.

Na semeadura foi utilizada, em ambos os experimentos, semeadora de arrasto com seis linhas, regulada para 6,2 sementes por metro linear. No primeiro ano avaliado o estande final foi de 60.000 plantas $a^{-1}$ e no segundo de 47.000 plantas ha ${ }^{-1}$. 
Nos dois anos agrícolas a área foi previamente dessecada utilizando o produto não seletivo Glifosato (glyphosate), na dosagem de $3,0 \mathrm{~L} \mathrm{ha}^{-1}\left(480 \mathrm{~g} \mathrm{~L}^{-1}\right)$. O tratamento fitossanitário das sementes foi realizado utilizando os inseticidas Imidacloprid $150 \mathrm{~g} \mathrm{~L}^{-1}+$ Tiodicarbe 450 $\mathrm{g} \mathrm{L}^{-1}$, na dosagem de $0,250 \mathrm{~L} \mathrm{ha}^{-1}$.

A adubação foi realizada mecanicamente, segundo recomendação para cultura do milho, utilizando $248 \mathrm{~kg} \mathrm{ha}^{-1}$, do formulado NPK 10-1515 , na base durante a semeadura. Com 30 dias após emergência (DAE), quando as plantas apresentavam-se no estádio fenológico V5 (cinco folhas completamente desenvolvidas), foi realizada a adubação nitrogenada, em cobertura, na dose de $110 \mathrm{~kg} \mathrm{ha}^{-1}$, utilizando como fonte a ureia ( $45 \%$ de $N$ ).

Os dados de temperaturas máxima e mínima e precipitação pluvial, referentes ao período de duração de cada um dos experimentos, encontram-se na Figura 1.

Figura 1. Temperaturas máxima e mínima e precipitação pluvial, por decêndio, no período de condução dos experimentos, safras 2014 e 2015 (Astorga, Estado do Paraná)

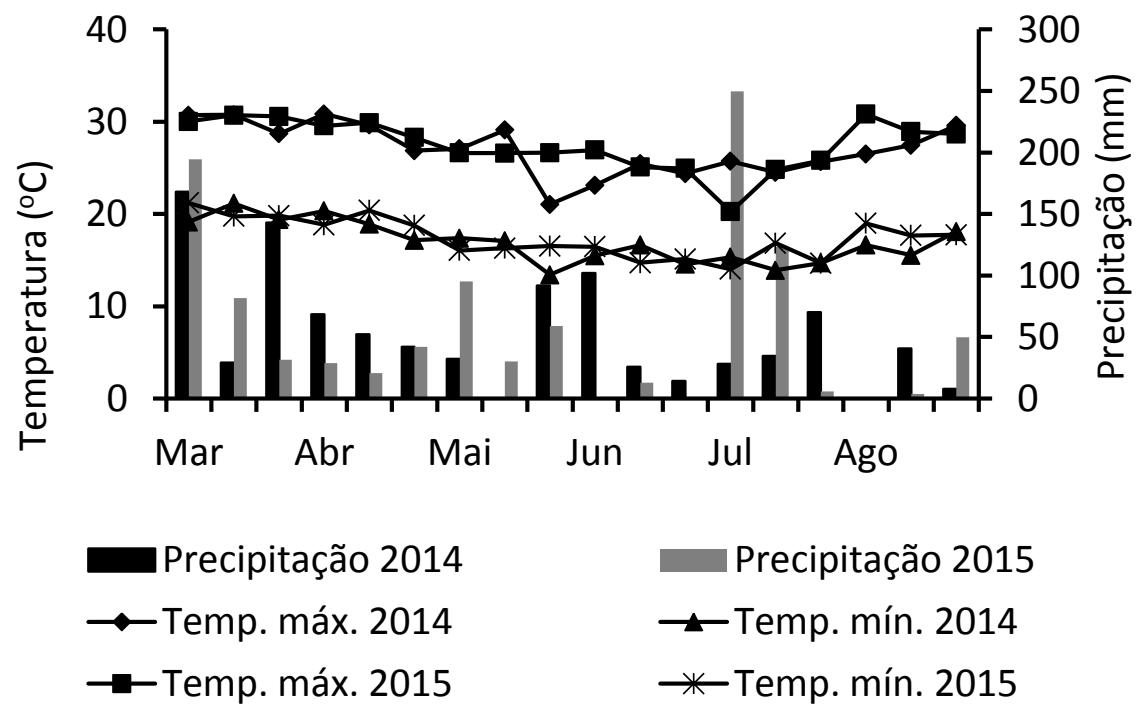

${ }^{1}$ Fonte: Estação Climatológica Principal de Maringá - Convênio UEM/INMET.

Nos dois experimentos foram avaliadas diferentes épocas de aplicação do fungicida Trifloxistrobina $100 \mathrm{~g} \mathrm{~L}^{-1}+$ Tebuconazol $200 \mathrm{~g} \mathrm{~L}^{-1}$, na dose comercial de $0,740 \mathrm{~L} \mathrm{ha}^{-1}+$ adição de óleo mineral, na dose de $0,540 \mathrm{~L} \mathrm{ha}^{-1}\left(720 \mathrm{~g} \mathrm{~L}^{-1}\right)$. O volume de calda utilizado foi de $125 \mathrm{~L} \mathrm{ha}^{-1}$.

Os tratamentos avaliados foram: 1) aplicação no estádio fenológico V8; 2) aplicação em Pré-Florescimento (V18); 3) aplicação em V8 + Pré-Florescimento e; 4) Testemunha, sem nenhuma aplicação. O delineamento utilizado foi o de blocos completos com tratamentos aleatorizados, com cinco repetições.

Cada parcela foi constituída de $5,4 \mathrm{~m}$ de largura por 5,5 m de comprimento, com seis linhas espaçadas em $0,90 \mathrm{~m}$ de largura, perfazendo $29,7 \mathrm{~m}^{2}$ de área total. Para fins de avaliação, foram analisadas as quatro linhas centrais de cada parcela com 4,5 m cada, resultando em uma área útil de $16,2 \mathrm{~m}^{2}$.

As características avaliadas foram severidade de doenças, massa de mil grãos e produtividade. Foram avaliadas as severidades dos fungos Puccinia sorghi, Exserohilum turcicum e Cercospora zeae-maydis, utilizando a escala diagramática desenvolvida pela Agroceres (1996), a qual apresenta escala de notas variando de 1 a 9, com área foliar afetada de $0 \%$ (sem dano), $0,5 \%, 10 \%, 30 \%, 50 \%, 70 \%, 80 \%, 90 \%$ e $100 \%$ para Puccinia sorghim; $0 \%, 1 \%, 10 \%, 20 \%, 30 \%$, 40\%, 60\%, $80 \%$ e > $80 \%$ para Exserohilum turcicum e Cercospora zeae-maydis.

Foram realizadas duas avaliações de severidade das doenças. Cada avaliação ocorreu em oito plantas escolhidas aleatoriamente, por parcela, nas quais foram obtidos os dados de severidade analisando-se quatro folhas da espiga e quatro folhas abaixo da espiga.

Os dados experimentais de cada variável foram submetidos à análise de variância individual para cada experimento (safra), a fim de verificar a possiblidade de realização da análise conjunta. As características submetidas à análise conjunta das safras foram as que atenderam a 
razão entre os quadrados médios residuais (QMR) de 7:1, conforme sugerido por Banzatto e Kronka (2006). Para as safras, empregou-se o teste $\mathrm{F}$ e na comparação das épocas de aplicação, foi utilizado o teste de Tukey, ambos a $5 \%$ de probabilidade. Os dados de severidade das doenças foram transformados em $\sqrt{y+1}$, visando atender os pressupostos básicos necessários à realização da análise de variância. Para a análise dos dados foi utilizado o software Sisvar (FERREIRA, 2011).

\section{Resultados e Discussão}

A análise de variância conjunta apresentou efeito significativo de tratamento para todas as características, pelo teste $\mathrm{F}$, a $5 \%$ de probabilidade, o que indica que a época de aplicação de fungicida para o controle das doenças foliares afetou, tanto as severidades das doenças avaliadas, como a produtividade e a massa de 1000 grãos (Tabela 1).

Tabela 1. Análise de variância conjunta para severidade de doenças, produtividade e massa de mil grãos da cultura do milho, cv. AG 9010, em função da época de aplicação do fungicida Trifloxistrobina + Tebuconazol, nas safras de 2014 e de 2015. Astorga, Estado do Paraná

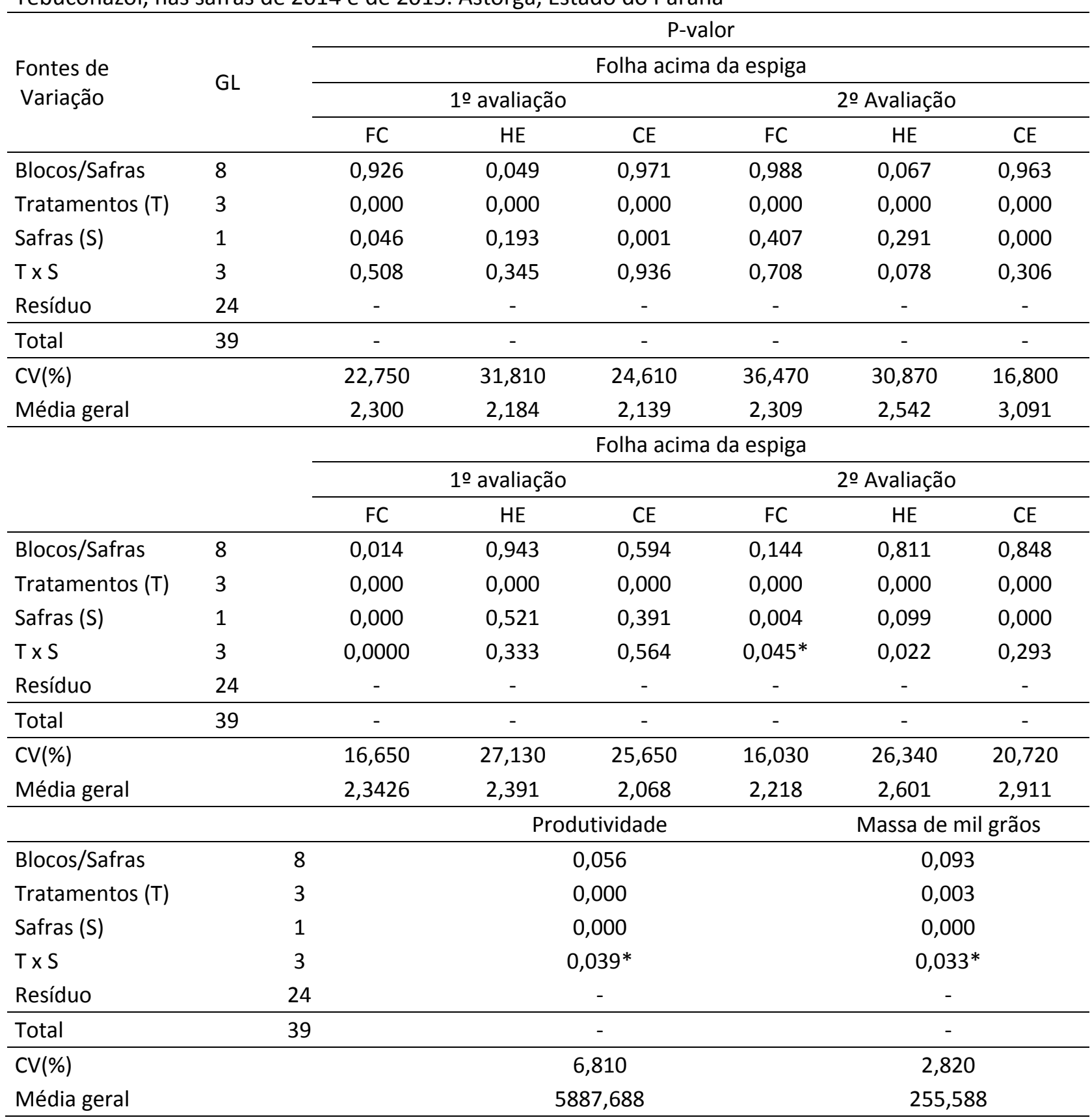

*Significativo em nível de $5 \%$ de probabilidade pelo teste $\mathrm{F}$.

GL: graus de liberdade, FC: Ferrugem Comum, HE: Helmintosporiose, CE: Cercosporiose. 
O coeficiente de variação (CV) foi baixo para os dados de produtividade e massa de mil grãos ora avaliados. Esses valores são similares aos obtidos por Brito et al., 2013 e Ecco et al., 2014 e indicam boa precisão experimental. No entanto, para as avaliações de severidade de doenças os CV's foram relativamente elevados. Tais valores podem ser explicados pela distribuição irregular do patógeno na área e estão de acordo com os observados por outros autores (BARROS, 2011; BRITO et al., 2011; FARIA et al., 2015, GRIGOLLI, 2016).

Segundo Banzatto e Kronka (2006), quando o efeito da interação tratamentos $x$ safras apresentar-se significativo, as médias dos tratamentos devem ser comparadas individualmente por safra. Ao contrário, quando este efeito não for significativo, os testes de comparação entre as médias dos tratamentos devem ser comparadas utilizando as médias entre todas as safras avaliadas nos experimentos. Dessa forma, a interação tratamentos $\mathrm{x}$ safras apresentou efeito significativo para severidade de Ferrugem Comum, quando avaliada a folha abaixo da espiga (primeira e segunda avaliação); Helmintosporiose, quando avaliada a folha abaixo da espiga (segunda avaliação), produtividade e massa de mil sementes. Assim, quando não se tratarem dessas situações, as comparações entre os tratamentos se deram pela média das duas safras estudadas.

O tratamento sem aplicação de fungicida (testemunha) apresentou maior severidade de Ferrugem Comum. Na primeira avaliação, a severidade desta doença apresentou diferenças significativas em função das épocas de aplicação avaliadas. Esses resultados estão de acordo com os encontrados por Juliatti et al. (2004) e Bonaldo et al. (2010), os quais observaram efeito positivo no controle da Ferrugem Comum, em todas as épocas de aplicação, em relação à testemunha. Por outro lado, Duarte et al. (2009) ao avaliarem diferentes fungicidas no controle da Ferrugem, observaram respostas distintas dos fungicidas, sobre o patógeno. Os autores verificaram que o fungicida Tebuconazol + Trifloxistrobina aplicado em V8 controlou a Ferrugem Comum do milho.

Tabela 2. Níveis médios da severidade (\%) de Ferrugem Comum (Puccinia sorghi) na cultura do milho, cv. AG 9010, em função da época de aplicação do fungicida Trifloxistrobina + Tebuconazol, nas safras de 2014 e de 2015. Astorga, Estado do Paraná

\begin{tabular}{|c|c|c|c|c|c|}
\hline \multirow{3}{*}{ Época de aplicação } & \multicolumn{2}{|c|}{ Folha abaixo da espiga } & \multicolumn{3}{|c|}{ Folha da espiga } \\
\hline & Safra & Safra & Safra & Safra & Média das \\
\hline & 2014 & 2015 & 2014 & 2015 & safras \\
\hline & \multicolumn{5}{|c|}{ Severidade na primeira avaliação (\%) } \\
\hline Testemunha & $20,63 \mathrm{~dB}$ & $8,75 \mathrm{bA}$ & 13,13 & 8,63 & $10,88 \mathrm{c}$ \\
\hline V8 & $10,88 c B$ & $1,75 \mathrm{aA}$ & 9,50 & 7,00 & $8,25 \mathrm{bc}$ \\
\hline Pré-Florescimento & $3,13 \mathrm{bB}$ & $1,13 \mathrm{aA}$ & 2,38 & 1,63 & $2,00 a b$ \\
\hline \multirow[t]{2}{*}{ V8 + Pré-Florescimento } & $0,38 \mathrm{aA}$ & $1,50 \mathrm{aA}$ & 0,38 & 0,38 & 0,38 a \\
\hline & \multicolumn{5}{|c|}{ Severidade na segunda avaliação (\%) } \\
\hline Testemunha & $15,13 \mathrm{bB}$ & $10,13 \mathrm{bA}$ & 15,63 & 9,50 & $12,56 \mathrm{~b}$ \\
\hline V8 & 3,00 aA & 2,63 aA & 6,13 & 6,88 & $6,50 \mathrm{ab}$ \\
\hline Pré-Florescimento & $1,50 \mathrm{aA}$ & $1,88 \mathrm{aA}$ & 3,00 & 1,75 & $2,38 \mathrm{a}$ \\
\hline V8 + Pré-Florescimento & $3,25 \mathrm{aB}$ & 0,88 aA & 0,88 & 0,63 & $0,75 \mathrm{a}$ \\
\hline
\end{tabular}

Médias seguidas de mesma letra, maiúscula na linha e minúscula na coluna, não diferem entre si a $5 \%$ de probabilidade pelo teste $\mathrm{F}$ e de Tukey, respectivamente.

A severidade da Ferrugem Comum apresentou-se com maior intensidade na safra de 2014, quando se observou a folha abaixo da espiga (Tabela 2). Provavelmente, as altas temperaturas e o ambiente úmido ocasionado pelas maiores precipitações no início do desenvolvimento da cultura favoreceram o aparecimento da doença, nesse ano agrícola. As diferenças notadas na folha abaixo da espiga podem estar relacionadas ao desenvolvimento da doença, que inicia da base em sentido ao ápice e, ou, pelo menor alcance do produto nas folhas basais da planta.

A eficiência no controle da Ferrugem se dá em função da aplicação dos fungicidas no aparecimento dos primeiros sintomas da doença, 
pois as ferrugens atacam as plantas de milho desde $\mathrm{o}$ estádio fenológico de V2 e, principalmente, as folhas inferiores (JULIATTI et al., 2004; DUARTE et al., 2009). Dessa forma, para que ocorra controle efetivo, deve haver monitoramento adequado para que, o controle com fungicida, seja feito no momento da observação das primeiras pústulas do patógeno. Essa medida visa tanto à redução da porcentagem de severidade da doença, quanto assegurar a produtividade da cultura (DUARTE et al., 2009). Por outro lado, Brandão et al. (2003) indicam que, controle utilizando fungicidas a partir do 45 DAE, seguido de uma ou duas aplicações no controle do fungo Cercospora zeaemaydis, apresentam efeito benéfico secundário no controle da Ferrugem. Além disso, os autores também relataram que o fungicida Tebuconazole foi eficaz no controle da doença. Tais apontamentos corroboram os resultados obtidos no presente estudo, visto que, o fungicida Tebuconazol juntamente com a Trifloxstrobina, em duas aplicações (V8 + Pré-Florescimento), possibilitaram menor severidade da Ferrugem, na safra de 2014.

Semelhantemente ao observado para Ferrugem Comum, os tratamentos em PréFlorescimento e V8 + Pré-Florescimento, não diferiram entre si e apresentaram controle significativamente superior para o agente etiológico Exserohilum turcicum (Tabela 3). A que se destacar que, na maioria das avaliações de Helmintosporiose, maior eficiência do fungicida em reduzir a severidade desta doença foi alcançada pela aplicação do produto em V8 + PréFlorescimento, quando comparado ao tratamento realizado somente em V8. Semelhantemente Silva et al. (2016) observaram redução na severidade de Helmintosporiose em função da época de aplicação do fungicida. Muito embora, o fungicida utilizado tenha sido diferente do ora avaliado, os autores destacaram que a aplicação sequencial de fungicida em V8 + VT (pendoamento) foi efetiva no controle da Helmintosporiose.

Tabela 3. Níveis médios da severidade (\%) de Helmintosporiose (Exserohilum turcicum) na cultura do milho, cv. AG 9010, em função da época de aplicação do fungicida Trifloxistrobina + Tebuconazol, nas safras de 2014 e de 2015. Astorga, Estado do Paraná

\begin{tabular}{lcccccc}
\hline \multirow{2}{*}{ Época de aplicação } & \multicolumn{3}{c}{ Folha abaixo da espiga } & \multicolumn{3}{c}{ Folha da espiga } \\
\cline { 2 - 7 } & Safra 2014 & Safra & Média das & Safra & Safra & Média das \\
safras & 2014 & 2015 & safras \\
\hline \multirow{3}{*}{ Testemunha } & \multicolumn{4}{c}{ Severidade na primeira avaliação (\%) } \\
V8 & 12,50 & 10,13 & $11,31 \mathrm{~b}$ & 8,13 & 10,13 & $9,13 \mathrm{~b}$ \\
Pré-Florescimento & 6,25 & 9,25 & $7,75 \mathrm{~b}$ & 3,25 & 9,50 & $6,38 \mathrm{ab}$ \\
V8 + Pré-Florescimento & 2,38 & 2,50 & $2,44 \mathrm{a}$ & 1,88 & 2,50 & $2,19 \mathrm{a}$ \\
\hline \multirow{y}{*}{ Testemunha } & 2,13 & 0,38 & $1,25 \mathrm{a}$ & 1,25 & 1,50 & $1,38 \mathrm{a}$ \\
V8 & \multicolumn{5}{c}{ Severidade na segunda avaliação (\%) } \\
Pré-Florescimento & $21,38 \mathrm{cB}$ & $10,25 \mathrm{bA}$ & \multicolumn{5}{c}{16,00} & 10,25 & $13,13 \mathrm{c}$ \\
V8 + Pré-Florescimento & $7,00 \mathrm{bA}$ & $9,88 \mathrm{bA}$ & 4,38 & 10,13 & $7,25 \mathrm{~b}$ \\
\hline
\end{tabular}

Médias seguidas de mesma letra, maiúscula na linha e minúscula na coluna, não diferem entre si a $5 \%$ de probabilidade pelo teste $\mathrm{F}$ e de Tukey, respectivamente.

Assim como nas outras doenças avaliadas (Tabelas 2 e 3), houve superioridade no tratamento cuja aplicação do fungicida foi efetuada em V8 + Pré-Florescimento e o mesmo foi eficiente em reduzir a severidade de Cercosporiose (Tabela 4). Esses resultados discordam dos observados por Bonaldo et al. (2010) e Silva et al. (2016), os quais não verificaram diferenças na severidade de Cercosporiose de acordo com o estádio de aplicação do fungicida. Entretanto, confirmam os de Fantin et al. (2008) e Brito et al. (2013). Brito et al. (2013) observaram severidade de Cercosporiose sempre menor que $10 \%$ de área foliar afetada, fato explicado pelo controle químico das doenças, o que possibilitou aos híbridos expressarem melhor seu potencial genético para a produção de grãos. 
Tabela 4. Níveis médios da severidade (\%) de Cercosporiose (Cercospora zeae-maydis) na cultura do milho, cv. AG 9010, em função da época de aplicação do fungicida Trifloxistrobina + Tebuconazol, nas safras de 2014 e de 2015. Astorga, Estado do Paraná

\begin{tabular}{lcccccc}
\hline \multirow{2}{*}{ Época de aplicação } & \multicolumn{3}{c}{ Folha abaixo da espiga } & \multicolumn{3}{c}{ Folha da espiga } \\
\cline { 2 - 7 } & Safra & Safra & Média das & Safra & Safra & Média das \\
& 2014 & 2015 & safras & 2014 & 2015 & safras \\
\hline \multirow{3}{*}{ Testemunha } & \multicolumn{5}{c}{ Severidade na primeira avaliação (\%) } \\
V8 & 11,88 & 10,50 & $11,19 \mathrm{~b}$ & 8,75 & 14,75 & $11,75 \mathrm{c}$ \\
Pré-Florescimento & 2,25 & 2,75 & $2,50 \mathrm{ab}$ & 2,75 & 5,88 & $4,31 \mathrm{~b}$ \\
V8 + Pré-Florescimento & 1,38 & 2,38 & $1,56 \mathrm{a}$ & 0,38 & 2,25 & $1,31 \mathrm{a}$ \\
\hline & 0,50 & 1,75 & $1,44 \mathrm{a}$ & 0,13 & 2,13 & $1,13 \mathrm{a}$ \\
Testemunha & \multicolumn{5}{c}{ Severidade na segunda avaliação (\%) } \\
V8 & 19,63 & 12,00 & $15,81 \mathrm{~b}$ & 23,75 & 15,13 & $19,44 \mathrm{~b}$ \\
Pré-Florescimento & 12,75 & 3,25 & $8,00 \mathrm{~b}$ & 11,13 & 6,50 & $8,81 \mathrm{ab}$ \\
V8 + Pré-Florescimento & 11,25 & 3,00 & $7,13 \mathrm{~b}$ & 10,25 & 2,50 & $6,38 \mathrm{a}$ \\
\hline
\end{tabular}

Médias seguidas de mesma letra, maiúscula na linha e minúscula na coluna, não diferem entre si a $5 \%$ de probabilidade pelo teste $\mathrm{F}$ e de Tukey, respectivamente.

No que concerne a época de aplicação, os resultados obtidos, corroboram aos encontrados por Juliatti et al. (2004), ao avaliarem diferentes híbridos de milho, com aplicação de diversos fungicidas concluíram que a aplicação aos 45 DAE possibilitaram o maior controle da Cercosporiose. Semelhantemente Barros (2011), verificou que a aplicação de azoxistrobina + ciproconazole proporcionou controle aceitável da Cercosporiose, especialmente em aplicação no Pré-Pendoamento do milho.

Os valores mais elevados de severidade de Ferrugem e Helmintosposriose, na safra de 2014 (Tabelas 3 e 4), além das condições de temperatura e umidade propícias ao seu desenvolvimento (Figura 1), podem estar relacionados à população de plantas. A mesma foi afetada pelas baixas precipitações durante a fase vegetativa e parte da fase reprodutiva da cultura, no ano de 2015 , levando a redução no estande final. Densidades mais elevadas proporcionam maior competição interespecífica por água, luz e nutrientes, além de proporcionar um microclima mais adequado ao desenvolvimento de doenças (SILVA et al., 2008).

Em relação à massa de mil grãos (MMG), a análise de variância conjunta indicou resultados significativamente superiores na safra de 2015 (Tabela 5). Nesta safra, a menor precipitação durante as fases vegetativa e início da reprodutiva (Figura 1 ) deve ter contribuído para a redução da população final de plantas, refletindo na MMG. Desse modo, possivelmente, as plantas compensaram a menor população pelo acúmulo de massa seca nos grãos. Por outro lado, a menor MMG, observada na safra de 2014, provavelmente foi função da maior população de plantas quando comparada à safra de 2015. Essa redução na MMG também foi observada por Serpa et al. (2012), quando houve incremento na densidade de plantas e, esse fator, de acordo com os autores, está ligado ao aumento da competição intraespecífica dos recursos presentes no ambiente. 
Tabela 5. Médias da massa mil grãos e produtividade da cultura do milho, cv. AG 9010, em função da época de aplicação do fungicida Trifloxistrobina + Tebuconazol, nas safras de 2014 e de 2015. Astorga, Estado do Paraná

\begin{tabular}{lcccc}
\hline \multirow{2}{*}{ Época de aplicação } & \multicolumn{2}{c}{ Massa de mil sementes $(\mathrm{g})$} & \multicolumn{2}{c}{ Produtividade kg ha $^{-1}$} \\
\cline { 2 - 5 } & Safra 2014 & Safra 2015 & Safra 2014 & Safra 2015 \\
\hline Testemunha & $225,7 \mathrm{aB}$ & $284,5 \mathrm{bA}$ & $6129,8 \mathrm{bA}$ & $4018,0 \mathrm{cB}$ \\
V8 & $224,3 \mathrm{aB}$ & $280,3 \mathrm{bA}$ & $6785,8 \mathrm{abA}$ & $5194,0 \mathrm{bB}$ \\
Pré-Florescimento & $216,3 \mathrm{aB}$ & $286,0 \mathrm{bA}$ & $6370,5 \mathrm{bA}$ & $5324,3 \mathrm{abB}$ \\
V8 + Pré-Florescimento & $226,9 \mathrm{aB}$ & $300,1 \mathrm{aA}$ & $7287,3 \mathrm{aA}$ & $5991,5 \mathrm{aB}$ \\
\hline Média geral & \multicolumn{3}{c}{255,6} & \multicolumn{2}{c}{5587,7} \\
CV (\%) & \multicolumn{2}{c}{2,8} & \multicolumn{2}{c}{6,8} \\
\hline
\end{tabular}

Médias seguidas de mesma letra, maiúscula na linha e minúscula na coluna, não diferem entre si a $5 \%$ de probabilidade pelo teste $\mathrm{F}$ e de Tukey, respectivamente.

No experimento avaliado em 2014 não houve diferenças na MMG em função das épocas de aplicação de fungicida (Tabela 5). Em contrapartida, no ano de 2015 a MMG de milho foi superior quando da aplicação do fungicida (Trifloxstrobina + Tebuconazol) em V8 + PréFlorescimento. Esses resultados corroboram aos verificados por Silva et al. (2016) na avaliação de diferentes híbridos de milho. Similarmente, Gonçalves et al. (2012) observaram o efeito positivo do tratamento sequencial com fungicida no aumento da massa de mil grãos de milho safrinha. Ainda, de acordo com Cunha et al. (2010) a aplicação de fungicida propicia à planta de milho melhores condições fisiológicas para a translocação de fotoassimilados em direção à espiga para o enchimento dos grãos, aumentando assim a massa dos mesmos. As estrobirulinas são responsáveis pela manutenção da atividade fotossintética da folha por maior período de tempo ("staygreen"), podendo chegar até o enchimento de grãos, favorecendo assim, a massa de grãos.

$\mathrm{Na}$ análise da produtividade verificou-se superioridade na safra de 2014, independente da época de aplicação do fungicida sobre a cultura (Tabela 5). Desse modo, ficou evidenciado que, na comparação das safras, houve resposta contrastante para as características de produtividade e massa de mil grãos de milho em função da aplicação do fungicida. Esses resultados corroboram os obtidos por Silva et al. (2008) e Calonego et al. (2011).

Semelhantemente aos resultados de severidade, a aplicação do fungicida em V8 + PréFlorescimento, em ambas as safras, teve efeito sobre a produtividade da cultura do milho. Este tratamento chegou a superar a testemunha em $1.157,5 \mathrm{~kg} \mathrm{ha}^{-1}$ e $1.973,5 \mathrm{~kg} \mathrm{ha}^{-1}(19,29$ e $32,89 \mathrm{sc}$ $\mathrm{ha}^{-1}$ ), nos anos de 2014 e 2015, respectivamente.
Maior produtividade também foi alcançada pela aplicação em V8 e em Pré-Florescimento, nos experimentos de 2014 e 2015, respectivamente. Isso mostra a eficiência do fungicida, o qual, ao controlar as doenças foliares pela redução na severidade, reflete em maior produtividade. Em experimentos similares, também foram observados tais efeitos (LAGO; NUNES, 2008; BRITO et al., 2012; SILVA et al., 2016). Ganhos na ordem de $917 \mathrm{Kg} \mathrm{ha}^{-1}$ na produtividade, foram obtidos por Lago e Nunes (2008), quando esses fungicidas foram aplicados no estádio V8. Em outro experimento, contudo, os melhores resultados de produtividade foram obtidos pelas aplicações dos mesmos fungicidas em V8 + VT (pendoamento) da cultura do milho (Silva et al. (2016), ou seja em duas aplicações.

Contrariando os resultados encontrados neste trabalho, Bonaldo et al. (2010) e Ecco et al. (2014) verificaram que a aplicação foliar de fungicida não refletiu em aumento de produtividade de milho de segunda safra. De maneira similar, Duarte et al. (2009) e Vilela et al. (2012) observaram que, embora a aplicação de fungicidas ocasionou redução na incidência e severidade de doenças, não refletiu em aumento produtividade.

Em geral, na comparação das épocas de aplicação do fungicida, observou-se que os maiores valores de produtividade coincidiram com a maior massa de grãos (safra de 2015) e com a menor severidade de doenças. Fantin et al. (2008) verificaram que, mesmo a partir de baixas severidades da mancha de Cercospora, já podem ser observadas reduções na produtividade do milho. Brito et al. (2013) reportaram elevação na produtividade de milho em Lavras, MG, em função da menor severidade de cercosporiose, além disso, afirmaram que a redução na produtividade é maior quando as doenças 
ocorrem precocemente. Analogamente, o efeito da aplicação de fungicidas na produtividade de grãos de milho já foi descrito por outros pesquisadores (BRITO et al., 2012; GONÇALVES et al., 2012; SILVA et al., 2016). Dessa forma, os resultados obtidos demonstraram a importância do ajuste da melhor época de aplicação, a qual, além de outros fatores como material genético, nível de severidade, tipo de doença, é determinante no controle de doenças intimamente ligadas com a queda da produtividade da cultura do milho safrinha.

\section{CONCLUSÕES}

As aplicações do fungicida Trifloxistrobina + Tebuconazol em Pré-Florescimento e V8 + PréFlorescimento reduziram a severidade de Cercosporiose e Helmintosporiose na cultura do milho de segunda safra.

A maior produtividade da cultura do milho foi obtida quando das aplicações de fungicida em V8 + Pré-Florescimento.

\section{REFERÊNCIAS}

AGROCERES. Guia Agroceres de sanidade. São Paulo: Sementes Agroceres, 1996. 72 p.

BANZATTO, D.A.; KRONKA, S.N. Experimentação agrícola. 4.ed. Jaboticabal: Funep, 2006. 237 p.

BARROS, R. Estudo sobre a aplicação foliar de acibenzolar-s-metil para indução de resistência à Ferrugem asiática em soja e Cercosporiose em milho. Arquivos do Instituto Biológico, v.78, n.4, p.519-528, 2011. http://dx.doi.org/10. $\underline{1590 / \text { S0100-54052006000300007 }}$

BONALDO, S.M.; DE PAULA, D.L.; CARRÉ-MISSIO, V. Avaliação da aplicação de fungicida em milho "safrinha" no munícipio de Boa EsperançaParaná. Campo Digit@I, v.5, n.1, p.1-7, 2010.

BRANDÃO, A.M.; JULIATTI, F.C.; BRITO, C.H.; GOMES, L.S.; VALE, F.X.R.; HAMAWAKI, O.T. Fungicidas e épocas de aplicação no controle da Ferrugem Comum (Puccinia sorghi Schw.) em diferentes híbridos de milho. Bioscience Journal, v.19, n.1, p.43-52, 2003.

BRITO, A.H.; PEREIRA, J.L.A.R.; PINHO, R.G. VON; BALESTRE, M. Controle químico de doenças foliares e grãos ardidos em milho (Zea mays L.). Revista Brasileira de Milho e Sorgo, v.11, n.1, p.49-59, 2012. http://dx.doi.org/10.18512/19806477/rbms.v11n1p49-59

BRITO, A.H.; VON PINHO, R.G.; PEREIRA, J.L.A.R.; BALESTRE, M. Controle químico da Cercosporiose, Mancha-Branca e dos Grãos Ardidos em milho. Revista Ceres, v.60, n.5, p.629635, 2013. http://dx.doi.org/10.1590/S0034$\underline{737 \times 2013000500005}$

BRITO, A.H.; VON PINHO, R.G.; SANTOS, A.O.; SANTOS, S. Reação de híbridos de milho e comparação de métodos para avaliação da Cercosporiose e Mancha branca. Tropical Plant Pathology, v.36, n.1, p.35-41, 2011. http://dx.doi.org/10.1590/S1982-

$\underline{56762011000100005}$

CALONEGO, J.C.; POLETO, L.C.; DOMINGUES, F.N.; TIRITAN, C.S. Produtividade e crescimento de milho em diferentes arranjos de plantas. Agrarian, v.4, n.12, p.84-90, 2011.

CONAB. Acompanhamento da safra brasileira de grãos: 9o Levantamento, junho/2018. v. 5 SAFRA 2017/18. https://www.conab.gov.br/infoagro/safras/graos

COSTA, D.F.; VIEIRA, B.S.; LOPES, E.A.; MOREIRA, L.C.B. Aplicação de fungicidas no controle de doenças foliares na cultura do milho. Revista Brasileira de Milho e Sorgo, v.11, n.1, p.95-105, 2012.

COSTA, R.V.; SILVA, D.D; COTA, L.V.; PARREIRA, D.F.; FERREIRA, A.S.; CASELA, C.R. Incidência de Colletotrichum graminicola em colmos de genótipos de milho. Summa Phytopathologica, v.36, p.122-128, 2010. http://dx.doi.org/10. 1590/S0100-54052010000200003

COTA, L. V.; SILVA, D. D.; COSTA, R. V. Helmintosporiose causada por Exserohilum turcicum na cultura do milho. Sete Lagoas: Embrapa Milho e Sorgo, 2013. 8 p. (Circular Técnica, 195). Disponível em: http://ainfo.cnptia.embrapa.br/digital/bitstream/ item/95096/1/circ-195.pdf. Acesso: 10 dez. 2018

CUNHA, J.P.A.R.; SILVA, L.L.; BOLLER, W.; RODRIGUES, J.F. Aplicação aérea e terrestre de fungicida para o controle de doenças do milho. Revista Ciência Agronômica, v.41, n.3, p.366-372, 
2010. http://dx.doi.org/10. 1590/S1806$\underline{66902010000300007}$

DUARTE, J. O.; MATTOSO, M. J. ; GARCIA, J. C. Agência Embrapa de Informação Tecnológica. Árvore do conhecimento: Milho, Embrapa, 2018. Disponível em: http://www.agencia.cnptia.embrapa.br/gestor/m ilho/arvore/CONTAG01 8 168200511157.html

DUARTE, R.P.; JULIATTI, F.C; FREITAS, P.T. Eficácia de diferentes fungicidas na cultura do milho. Bioscience Journal, v.25, n. 4, p. 101-111, 2009.

ECCO, M.; ROSSET, J.S.; RAMPIM, L.; COSTA, A.C. T.; LANA, M.C.; STANGARLIN, J.R.; SARTO, M.V.M. Características agronômicas de híbridos de milho segunda safra submetidos à aplicação de fungicida. Revista Agrarian, v.7, n.26, p.504-510, 2014.

FANCELLI, A.L. Influência do desfolhamento no desempenho de plantas e de sementes de milho (Zea mays L.). 1988. 172p. Tese (Doutorado em Agronomia) - Escola Superior de Agricultura Luiz de Queiroz, Universidade de São Paulo, Piracicaba, 1988.

FANTIN, G.M.; DUARTE, A.P.; DUDIENAS, C.; GALLO, P.B.; RAMOS JÚNIOR, E.U.; CRUZ, F.A.; RAMOS, V.J.; FREITAS, R.S.; DENUCCI, S.; TICELLI, M. Efeito da mancha de cercospora na produtividade do milho safrinha, no Estado de São Paulo. Revista Brasileira de Milho e Sorgo, v.7, n.3, p. 231-250, 2008.

FARIA, M.V.; MENDES, M.C.; ROSSI, E.S.; POSSATTO JUNIOR, O.; RIZZARDI, D.A.; GRALAK, E.; SILVA, C.A.; FARIA, C.M.D.R. Análise dialélica da produtividade e do progresso da severidade de doenças foliares em híbridos de milho em duas densidades populacionais. Semina: Ciências Agrárias, v.36, n.1, p.123-134, 2015. http://dx.doi.org/10. 5433/1679$\underline{0359.2015 v 36 n 1 p 123}$

FERREIRA, D.F. Sisvar: a computer statical analysis system. Ciência e Agrotecnologia, v. 35, n. 6, p. 1039-1042, 2011. http://dx.doi.org/10. $\underline{1590 / \text { S1413-70542011000600001 }}$

GONÇALVES, M.E.M.P.; GONÇALVES JUNIOR, D.; SILVA, A.G.; CAMPOS, H.D.; SIMON, G.A.; SANTOS, C.J.L.; SOUSA, M.A. Viabilidade do controle químico de doenças foliares em híbridos de milho no plantio de safrinha. Nucleus, v.9, n.1, p.49-62, 2012.

GRIGOLLI, J.F.J. Doenças do milho safrinha. In: MELOTTO, A. M.; LOURENÇÃO, A. L. F.; GITTI, D. C.; GRIGOLLI, J.F.J. Tecnologia e Produção: milho safrinha 2015. Curitiba: Midiograf, 2016. p.101120.

JULIATTI, F.C.; APPELT, C.C.N.S.; BRITO, C.H.; GOMES, L.S.; BRANDÃO, A.M.; HAMAWAKI, O.T.; MELO, B. Controle da feosféria, Ferrugem Comum e Cercosporiose pelo uso da resistência genética, fungicidas e épocas de aplicação na cultura do milho. Bioscience Journal, v.20, n.3, p45-54, 2004.

KIST, B. B.; FILTER, C. F.; SANTOS, C. E. dos; CARVALHO, C. Anuário brasileiro do milho 2018. Santa Cruz do Sul: Editora Gazeta Santa Cruz, 2018. 88 p.

LAGO, F.L.; NUNES, J. Avaliação da produtividade de milho em relação à aplicação de fungicidas em diferentes estádios. Cultivando o saber, v.1, p. 17-23, 2008.

PATAKY, J.K. Relationships between yield of sweet corn and northern leaf blight caused by Exsohilum turcicum. Phytopathology, v.82, n.3, p.370-375, 1992.

SERPA, M. S.; SILVA, P.R.F. ; SANGOI, L.; VIEIRA, V.M.; MARCHESI, D.R. Densidade de plantas em híbridos de milho semeados no final do inverno em ambientes irrigados e de sequeiro. Pesquisa Agropecuária Brasileira, v.47, n.4, p.541-549, $2012 . \quad$ http://dx.doi.org/10.1590/S0100204X2012000400010

SILVA, A.G.; FRANCISCHINI, R.; TEIXEIRA, I.R.; PAIVA, M.M. Aplicação de fungicida em híbridos de milho na safra de verão na região Central do Brasil. Magistra, v.28, n.3/4, p.379-389, 2016.

SILVA, A.G.; CUNHA JUNIOR, C.R.; ASSIS, R.L.; IMOLESI, A.S. Influência da população de plantas e do espaçamento entre linhas nos caracteres agronômicos do híbrido de milho P30K75 em Rio Verde, Goiás. Biosciense Journal, v.24, n. 2, p.8996, 2008 
SILVA, R.R.; THEODORO, G.F.; LIBÓRIO, C.B.; PESSOA, L.G.A. Influência da densidade de cultivo de genótipos de milho na severidade da mancha de cercospora e no rendimento de grãos na 'safrinha'. Semina: Ciências Agrárias, v.33, n.4, p.1449-1454, 2012.

http://dx.doi.org/10.5433/1679-

$\underline{0359.2012 v 33 n 4 p 1449}$

VILELA, R.G.; ARF, O.; KAPPES, C.; KANEKO, F.H.; GITTI, D.C.; FERREIRA, J.P. Desempenho agronômico de híbridos de milho, em função da aplicação foliar de fungicidas. Bioscience Journal, v.28, v.1, p.25-33, 2012. 